\title{
Experimental investigation of a new low-temperature hot stamping process for boron steels
}

\author{
M. Ganapathy ${ }^{1,2} \cdot$ N. Li ${ }^{3}$ (D) J. Lin ${ }^{1} \cdot$ M. Abspoel ${ }^{4} \cdot$ D. Bhattacharjee ${ }^{2}$
}

Received: 12 March 2019 / Accepted: 17 July 2019 / Published online: 13 August 2019

(C) The Author(s) 2019

\begin{abstract}
This paper demonstrates the promise of a new low-temperature hot stamping process with pre-cooling for 22MnB5 boron steels. It is the first time for the new process being successfully implemented for producing an automotive demonstrator component assisted with thorough experimental studies. The studies mainly include hot forming experiments carried out on an industrial prototyping line, post-form examinations, and in-die quenching tests. Automotive B-Pillar components with two designed drawing depths (50 and $64 \mathrm{~mm}$ ) were hot stamped at a wide range of temperatures and forming speeds, through both the conventional hot stamping processes and the new processes with pre-cooling applied. For the as-formed B-Pillars, 3D shape scanning was conducted to investigate the thickness distribution of the components; uniaxial tensile testing, hardness testing, and scanning electron microscopes (SEM) observation were conducted to assess the final mechanical properties and microstructures. To understand the benefit of the low-temperature hot stamping in reducing cycle time, a separate set of in-die quenching experiments were designed and carried out, with combinations of three different process parameters: workpiece start quenching temperature, initial tool temperature, and dieworkpiece contact pressure. The results of this work confirmed that low-temperature hot stamping could be performed successfully in producing complex-shaped components, such as automotive B-Pillars, with much reduced cycle time.
\end{abstract}

Keywords Low-temperature hot stamping $\cdot$ Boron steels $\cdot$ In-die quenching $\cdot$ Post properties $\cdot$ Productivity

\section{Introduction}

The application of ultra-high-strength steels (boron steels) is increasing, particularly in the automotive industry, since it is critical for reducing the vehicle weight and fuel consumption, with improved safety performance. To meet stringent safety and environmental regulations [1], the consumption of hotstamped boron steels has dramatically increased in the last decade and is estimated to increase further [2]. At the same time, technological innovations to reduce the process cycle

N. Li

n.li09@imperial.ac.uk

1 Department of Mechanical Engineering, Imperial College London, London SW7 2AZ, UK

2 Tata Steel Ltd., Jamshedpur, India

3 Dyson School of Design Engineering, Imperial College London, London SW7 2AZ, UK

4 Tata Steel, IJmuiden, Netherlands time of hot stamping, thus improve productivity, are highly demanded.

In conventional hot stamping processes, the stamping temperature is about $700-800{ }^{\circ} \mathrm{C}$. At this temperature range, the material is softer and more ductile. However, a higher temperature also results in materials with a lower strain hardening exponent ( $n$ value). Materials with a lower $n$ value would have less drawability than those with higher $n$ values $[3,4]$. In addition, in hot stamping, the temperature drop of the hot blank is higher at tool contact region compared with noncontact wall region. As a result, localised straining tends to occur due to higher temperature which caused lower strength in these regions. The temperature non-uniformity is increased when the stamping temperature is higher.

In hot stamping, although the cooling rate of the material during in-die quenching is always desired to be as high as possible to minimise cycle time, it normally takes about 10 $20 \mathrm{~s}$ to quench a boron steel blank from 800 to $250{ }^{\circ} \mathrm{C}$ (depending on die pressure and blank thickness) within a pressurised die set, which is determined by the thermal conductivity and heat transfer coefficients of the tool and blank materials [5-7]. Further reduction in in-die quenching time 
Table 1 Chemical composition of 22MnB5 boron steel provided by Tata Steel in weight percent

\begin{tabular}{llllllllll}
\hline Material grade & $\mathrm{C}$ & $\mathrm{Mn}$ & $\mathrm{Si}$ & $\mathrm{Cr}$ & $\mathrm{S}$ & $\mathrm{B}$ & $\mathrm{Ti}$ & $\mathrm{Nb}$ & $\mathrm{Ni}$ \\
\hline $22 \mathrm{MnB5}$ & 0.20 & 1.17 & 0.25 & 0.20 & 0.002 & 0.0029 & 0.028 & 0.001 & 0.023 \\
\hline
\end{tabular}

(thus cycle time) is difficult, which hindered the improvement in productivity. Moreover, the tooling cost for hot stamping is high because of die cooling arrangements and hightemperature die wear. The die temperature increases due to high stamping temperature of boron steel [8,9]. The employed elevated temperature and relative movement between the tool and blank lead to an increased wear rate of the tool, reducing its lifetime $[10,11]$.

To overcome the above limitation, the idea of heating the steel to $900{ }^{\circ} \mathrm{C}$ for complete austenitisation and stamping the material in austenitic state at a reduced temperature through fast cooling was proposed through patents by Balint et al. [12] and Ota et al. [13]. Hot stamping experiments were conducted by Chang et al. [14] and Li et al. [15] for medium-Mn steel at a range of forming temperatures $400-650{ }^{\circ} \mathrm{C}$ and found that deformation at a lower temperature range increased the strain hardening exponent ( $n$ value). The suitable forming temperature range for medium-Mn steel was between 450 and $500{ }^{\circ} \mathrm{C}$ for better drawability with higher $n$ values. Similar process is potentially to be adopted for 22MnB5 boron steel. However, in the case of medium-Mn steel, a rapid cooling process was not needed due to its reduced requirement of cooling rate; while for boron steels, fast cooling is critically required for obtaining full martensite in the formed parts. The critical cooling rate for undeformed boron steels is around $27^{\circ} \mathrm{C} / \mathrm{s}$, but it can be significantly higher, such as than $80{ }^{\circ} \mathrm{C} / \mathrm{s}$, for deformed boron steels [16]. Therefore, to control the microstructure, enforced cooling must be applied to decrease the material temperature quickly before forming when $22 \mathrm{MnB} 5$ boron steel is stamped at a reduced temperature (e.g. $500{ }^{\circ} \mathrm{C}$ ). To address the needs, the Metal Forming group at Imperial College London proposed a hot stamping method with integrated pre-cooling to produce complex-shaped parts [12]. In this case, hot boron steel is rapidly cooled to a predefined temperature between furnace and press by an intermediate cooling setup, which can apply high heat conductive device, air jet, or liquid mist spray. Then the forming could be done at a lower temperature range just above martensitic transformation start temperature. The material strain hardening is improved at a lower temperature, which benefits in better drawability [17].

Tata Steel also explored the concept of pre-cooling in hot stamping to avoid or reduce the micro-cracking issue with zinc-coated boron steel [18]. Zn-coated boron steel was used in the hot stamping process. Zn coating was likely to produce micro-cracks which also affected the substrate material, which was not acceptable for the automotive application. It was observed that the starting of micro-cracks was due to high temperature of $\mathrm{Zn}$-coated boron steel during hot stamping, while the material stamped at low-temperature resulted in reduced number and depth of the micro-cracks significantly. In this concept, forming of zinc-coated boron steel at the reduced temperature between 500 and $740{ }^{\circ} \mathrm{C}$ was proposed.

It appears that there are also many patents available on the similar principle but with different objectives. Schuler [19] and Gestamp Hardtech [20] proposed a technique to increase the tool life and reduce the cycle time. To improve the material performance during hot stamping, Tata Steel [18], Nippon Steel and Sumitomo Metal [21], ThyssenKrupp [22], and Kobe Steel [23] focused on hot stamping at low temperature. Auto parts manufacturers like Toyota and Aisin Takaoka [24], Voestalpin [25], and Magna Cosma [26] aimed to improve the quality of the final product during hot stamping. However, detailed research on the above-proposed patents was not found in a literature.

The aim of this work was to conduct a systematic study experimentally on the novel process of low-temperature hot stamping. The objectives are to produce complex-shaped automotive B-Pillar demonstrators through the new method, to examine the post-form quality in terms of geometry (e.g. thickness) and mechanical properties, and to investigate the potential in reducing in-die quenching time, by comparing the
Fig. 1 Hot stamping with precooling (green - a new process) and without pre-cooling (red-a conventional process) illustrated in the CCT diagram (a) and temperature profile (b) of the test programme

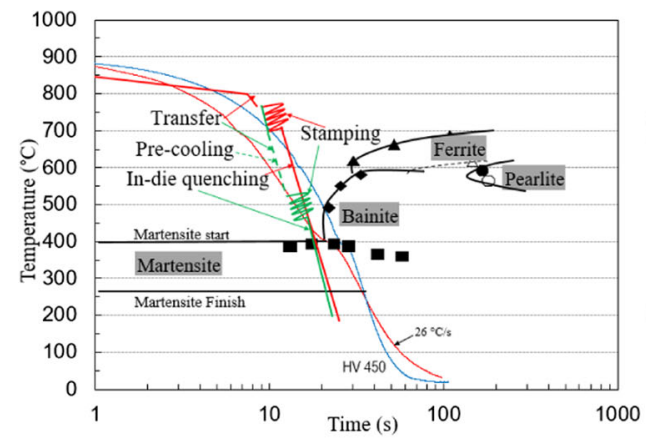

(a)

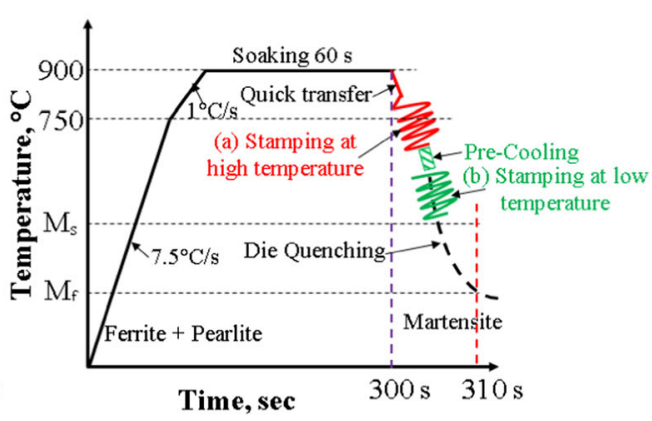

(b) 
(a) Conventional hot stamping Process

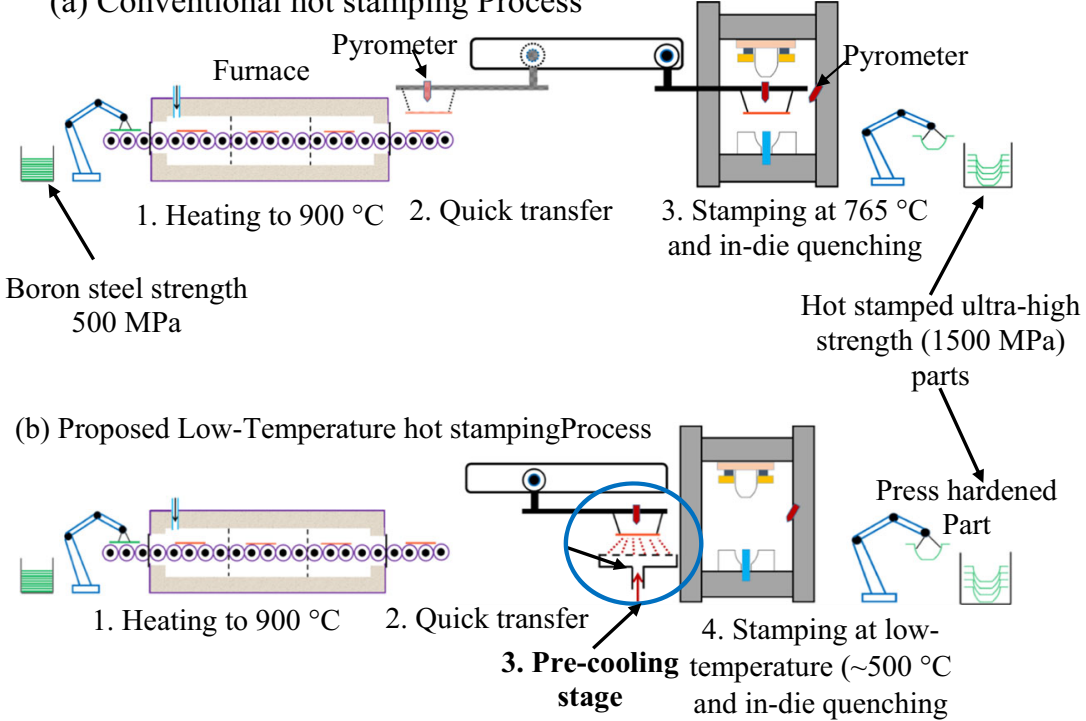

Fig. 2 Concept illustration for (a) a conventional hot stamping process and (b) a new hot stamping process with pre-cooling [27]

results obtained from the new and the conventional hot stamping processes.

\section{Experimental details of hot stamping experiments}

An uncoated 22MnB5 boron steel with a thickness of $1.5 \mathrm{~mm}$ provided by Tata Steel was used as test material. The initial microstructure of the test material is ferrite-pearlite, and its chemical composition is given in Table 1. The typical continuous cooling transformation (CCT) diagram for this material was provided by Tata Steel and shown in Fig. 1a. As the CCT diagram shows, for the as-delivered material, a minimum cooling rate is $26^{\circ} \mathrm{C} / \mathrm{s}$ to ensure complete martensitic phase transformation. In this paper, the new process was studied through hot stamping experiments for forming a series of automotive B-Pillar demonstration components. Experiments were performed at various forming temperatures and speeds, achieved through both conventional (without pre-cooling) and new (with pre-cooling) hot stamping processes. The thickness of hot-stamped B-Pillars was scanned using an optical blue light scanner for thickness measurement. The post-formed mechanical properties and microstructures were examined through hardness test, tensile tests, and SEM observation. Moreover, to understand the significance of the new hot stamping process in reducing cycle time, in-die quenching experiments were carried out. Details of each part of the work are introduced in the following subsections.

\subsection{Hot stamping of B-Pillars through the conventional and new processes}

Schematic illustration of the experimental setup for both the conventional and new hot stamping processes is shown in Fig. 2(a) and (b), respectively. In a conventional process, the equipment consisted of a furnace for heating the blank, a feeder to quickly transfer the blank, and a stamping press with a set of B-Pillar tool assembly. After heating, austenitized boron steel was quickly transferred to the stamping press and placed on the B-Pillar tool for forming the product with martensitic microstructure. In the new process, a pre-cooling stage was incorporated between the furnace and the stamping press.

Both a conventional hot stamping process of boron steel and a new process are described in Fig. 1, using a red line and a green line, respectively. As shown in Fig. 2, for each forming experiment, an electrically heated roller hearth furnace was

Table 2 Time spent on sub-stages of transfer from furnace to stamping die and the resulted start stamping temperatures corresponding to different precooling time

\begin{tabular}{|c|c|c|c|c|c|c|c|}
\hline $\begin{array}{l}\text { Soaking } \\
\text { temperature }\left({ }^{\circ} \mathrm{C}\right)\end{array}$ & $\begin{array}{l}\text { Furnace out to } \\
\text { end of roller (s) }\end{array}$ & $\begin{array}{l}\text { Roller to } \\
\text { pre-cooling (s) }\end{array}$ & $\begin{array}{l}\text { Pre-cooling } \\
\text { time (s) }\end{array}$ & $\begin{array}{l}\text { Pre-cooling to } \\
\text { position on the die (s) }\end{array}$ & $\begin{array}{l}\text { Waiting time } \\
\text { on the die (s) }\end{array}$ & $\begin{array}{l}\text { Total } \\
\text { time }(\mathrm{s})\end{array}$ & $\begin{array}{l}\text { Start stamping } \\
\text { temperature }\left({ }^{\circ} \mathrm{C}\right)\end{array}$ \\
\hline \multirow[t]{4}{*}{900} & \multirow[t]{4}{*}{1.9} & \multirow[t]{4}{*}{5.6} & 0 & \multirow[t]{4}{*}{0.7} & \multirow[t]{4}{*}{0.3} & 8.5 & 765 \\
\hline & & & 0.4 & & & 8.9 & 700 \\
\hline & & & 1.8 & & & 10.3 & 590 \\
\hline & & & 3.3 & & & 11.8 & 500 \\
\hline
\end{tabular}


Fig. 3 B-Pillar hot stamping. a BPillar die assembly in the stamping press. b Cross-sectional schematics illustrating the work mechanism of the die set (the red line being deformed represents the hot blank). 1) Beginning of hot stamping. 2) During hot stamping. 3) End of hot stamping. c The designed blank profile. d Austenitic blank on roller right after heating

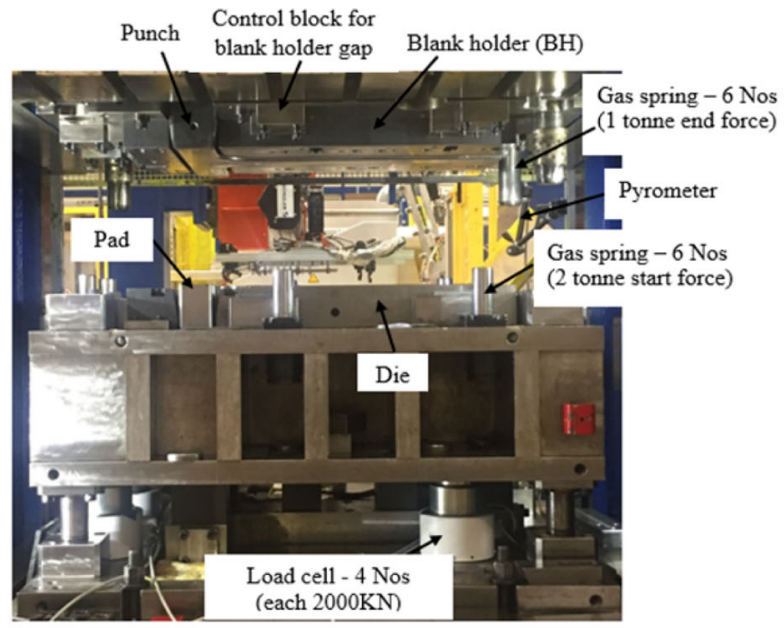

(a) B-Pillar die assembly in the stamping press.

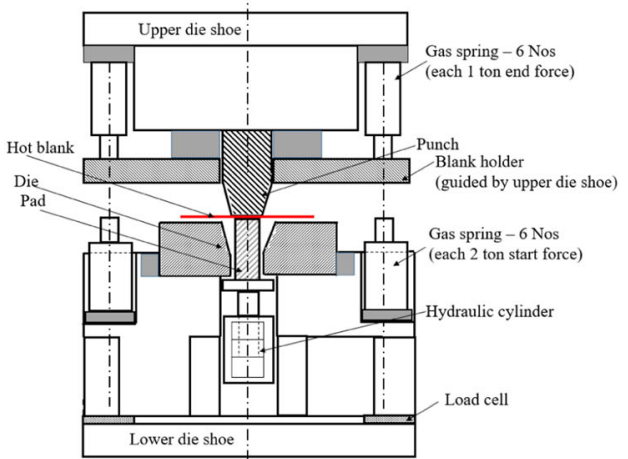

1) Beginning of hot stamping

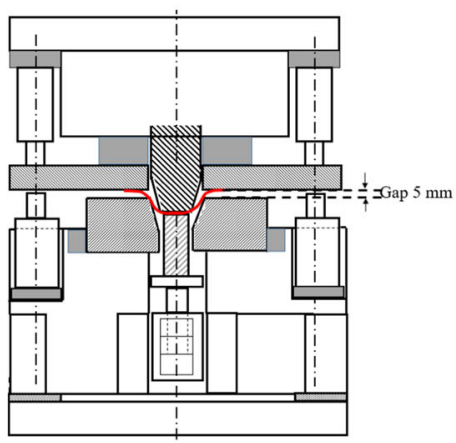

2) During hot stamping

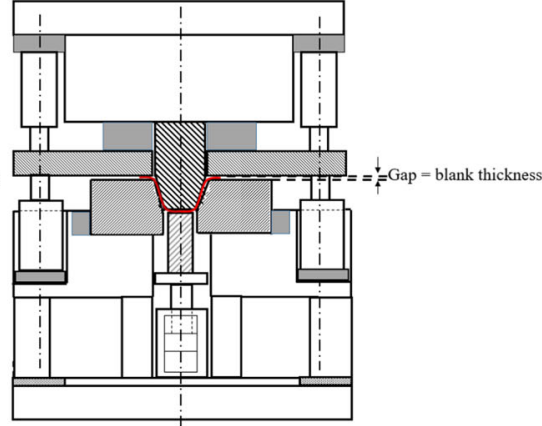

3) End of hot stamping

(b) Cross-sectional schematics illustrating the work mechanism of the die set (the red line being deformed represents the hot blank).

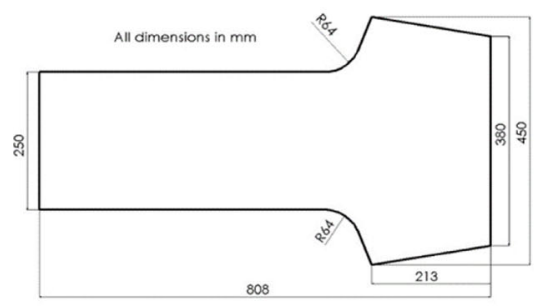

(c) The designed blank profile.

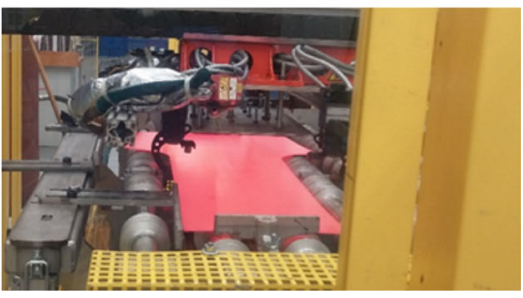

(d) Austenitic blank on roller right after heating. 
used for heating the boron steel. To prevent decarburisation and scale formation, the heating was performed in the nitrogen atmosphere. The material was heated up to $750{ }^{\circ} \mathrm{C}$ at a targeted heating rate of $7.5^{\circ} \mathrm{C} / \mathrm{s}$ followed by a slower, targeted heating rate of $1{ }^{\circ} \mathrm{C} / \mathrm{s}$ up to $900^{\circ} \mathrm{C}$ and held at $900{ }^{\circ} \mathrm{C}$ for about $60 \mathrm{~s}$ for homogenisation, suggested by Tata Steel. Corresponding to a new process, the austenised boron steel was quickly transferred to pre-cooling stage for rapid cooling to a desired start stamping temperature. Pre-cooling was done at a cooling rate of greater than $60{ }^{\circ} \mathrm{C} / \mathrm{s}$ with the help of compressed air at 10 bar pressure. Pre-cooling plates which consist of multiple tiny holes were adopted to ensure uniform cooling during the pre-cooling process. To monitor and control the temperature of the blank material during transfer and pre-cooling, calibrated non-contact digital infrared thermometers (pyrometers) were attached to both the feeder and stamping press. Due to fast cooling, even though the austenised boron steel was pre-cooled to a low temperature down to below 500 ${ }^{\circ} \mathrm{C}$, the material could still be in the austenitic condition for hot stamping. Under a designed forming speed, the stamping process was intended to complete before the austenite start to break down into martensitic, which is around $425{ }^{\circ} \mathrm{C}$ [28]. Subsequently, in-die quenching for $20 \mathrm{~s}$ further decreased the temperature of boron steel to below martensite transformation finish temperature $\left(280{ }^{\circ} \mathrm{C}\right)$ and resulted in an ultra-highstrength product predominately with martensitic steel.

The transfer time from furnace out to positioning on the stamping die at various stages is listed in Table 2, which is specific to this hot stamping setup and can be further reduced by adjusting the distance between the furnace, pre-cooling device, and stamping press. By defining different precooling time, different start stamping temperatures can be resulted. As shown in Table 2, without pre-cooling (i.e. the precooling time is $0 \mathrm{~s}$ ), the start stamping temperature is $765^{\circ} \mathrm{C}$, which represents a conventional stamping process; by increasing the pre-cooling time, the start stamping temperature could drop gradually, which represents the new stamping processes with deformation taking place at a lower temperature range.

The setup of the B-Pillar die set installed on a hydraulic press is shown in Fig. 3a. The work mechanism of the die set is illustrated through the schematics given in Fig. 3b: (1) Pad

Table 3 B-Pillars hot stamped to the depth of $50 \mathrm{~mm}$ under various process conditions (' $\checkmark$ ' represents that the component was formed without necking/fracture; ' $X$ ' represents that necking/fracture occurred)

\begin{tabular}{lccccc}
\hline Forming speed, $\mathrm{mm} / \mathrm{s}$ & \multicolumn{5}{c}{ Actual start stamping temperature, ${ }^{\circ} \mathrm{C}$} \\
\cline { 2 - 6 } & 765 & 590 & 540 & 440 & 420 \\
\hline 60 & $\checkmark$ & & & $\checkmark$ & $\times$ \\
150 & $\checkmark$ & $\checkmark$ & $\checkmark$ & $\checkmark$ & $\times$ \\
350 & $\checkmark$ & & & $\checkmark$ & $\times$ \\
\hline
\end{tabular}

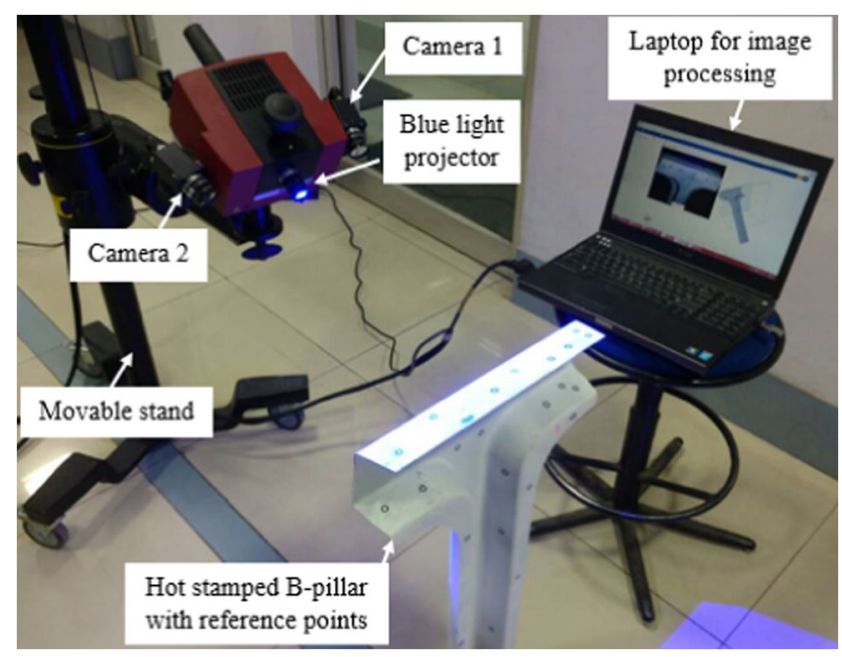

Fig. 4 Thickness measurement by using a 3D scanning with ATOS Compact Scan 2M

from the bottom of the tool pushes the blank against the punch with $200 \mathrm{kN}$ force, simultaneously, blank holder moves very close to the blank with spacer clearance of $5 \mathrm{~mm}$. (2) Punch moves down to form the B-Pillar shape. (3) Finally, at the end of forming during the press hardening process, punch pushes the blank against die and pad, and instantaneously, blank holder closes completely in order to cool the blank quickly to make martensitic component.

In this study, the B-Pillar demonstration components were defined as two drawing depth, $50 \mathrm{~mm}$ and $64 \mathrm{~mm}$, by changing the die sets. For the different drawing depths, the same blank shape was used. The geometry and dimensions of the blank profile, determined through preliminary studies, are shown in Fig. 3c, with a picture of a heated blank on roller given in Fig. 3d. For each drawing depth, hot stamping experiments were conducted at a range of different start stamping temperatures $\left(420-765^{\circ} \mathrm{C}\right)$ and at a range of different forming speeds $(60-350 \mathrm{~mm} / \mathrm{s})$. It is noted that the temperatures are actual start stamping temperatures confirmed through the non-

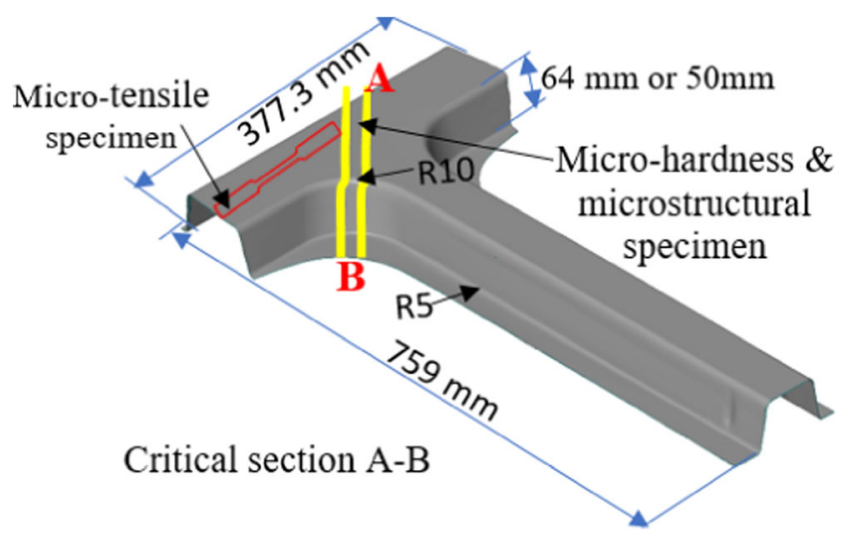

Fig. 5 The scanned 3D polygon model of a B-Pillar and the locations for mechanical testing and microstructural observation 
Fig. 6 Dimensions of the sub-size tension test specimen cut from hot-stamped B-Pillar parts

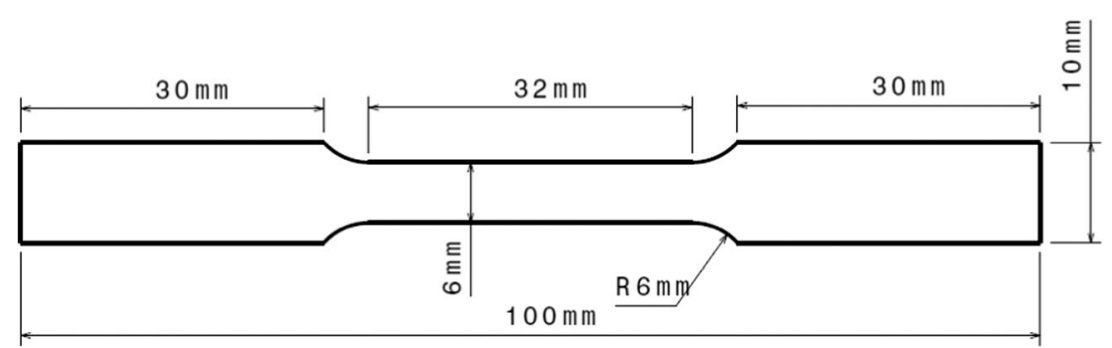

contact digital infrared thermometer installed on the press. For $765{ }^{\circ} \mathrm{C}$, no pre-cooling was applied; for the rest of the temperatures, pre-cooling was applied. Under the same forming speed, it should take longer to form a component with greater drawing depth, thus the blank would experience greater temperature drop during forming due to heat loss to cold dies, which indicates a higher potential of crossing the martensite phase transformation temperature. Therefore, when precooling was applied, the temperature range defined for forming the components with $64 \mathrm{~mm}$ depth (listed in Table 4) was slightly higher than that for $50 \mathrm{~mm}$ depth (listed in Table 3).

\subsection{Post-form examination of the hot-stamped B-Pillars}

The success of a forming process should be validated by the fact that the as-form components can achieve both the required geometry (e.g. thickness) and required properties. Therefore, two sets of post-form examination were designed and carried out on the hot-stamped B-Pillars.
1. 3D scanning for measuring as-formed thickness thinning

Hot-stamped B-Pillars were analysed in terms of maximum thinning, measured by using a set of 3D optical blue light scanner. The complete arrangement of the scanner, movable stand, and a B-Pillar marked with reference points is shown in Fig. 4. In order to obtain the thickness distribution, scanning was performed at both inside and outside surfaces of the B-Pillar. The scanned point clouds were transformed into $3 \mathrm{D}$ polygon surfaces (refer to Fig. 5).

2. Mechanical testing and microstructural observation for as-formed properties

To confirm the hot stamping property requirements, tensile and micro-hardness samples were prepared from B-Pillar parts; those were hot stamped through both the conventional and new hot stamping processes. The specimen selection and property evaluation are only for relative comparison between the conventional and new hot stamping process. The sample cut out region in B-Pillar is shown in Fig. 5. Hardness and
Fig. 7 B-Pillars hot stamped to the depth of $50 \mathrm{~mm}$ under various start stamping temperatures: a $765^{\circ} \mathrm{C}$, b $440{ }^{\circ} \mathrm{C}$, and $\mathbf{c} 420^{\circ} \mathrm{C}$, at the forming speed of $150 \mathrm{~mm} / \mathrm{s}$
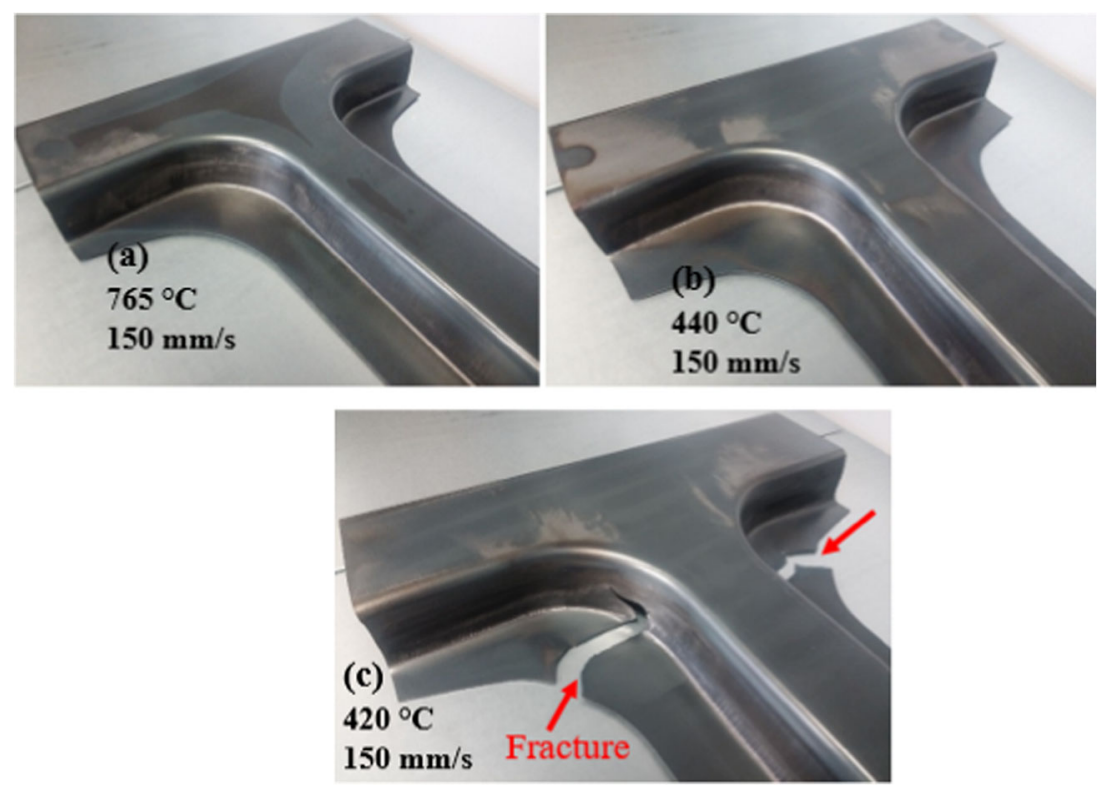
Fig. 8 B-Pillars hot stamped to the depth of $64 \mathrm{~mm}$ under various process conditions: a $765^{\circ} \mathrm{C}$ with the forming speed of $150 \mathrm{~mm} / \mathrm{s}, \mathbf{b}$ $500{ }^{\circ} \mathrm{C}$ with the forming speed of $150 \mathrm{~mm} / \mathrm{s}, \mathbf{c} 500^{\circ} \mathrm{C}$ with the forming speed of $60 \mathrm{~mm} / \mathrm{s}$, and $\mathbf{d}$ $450{ }^{\circ} \mathrm{C}$ with the forming speed of $150 \mathrm{~mm} / \mathrm{s}$ (the temperatures given were start stamping temperatures)
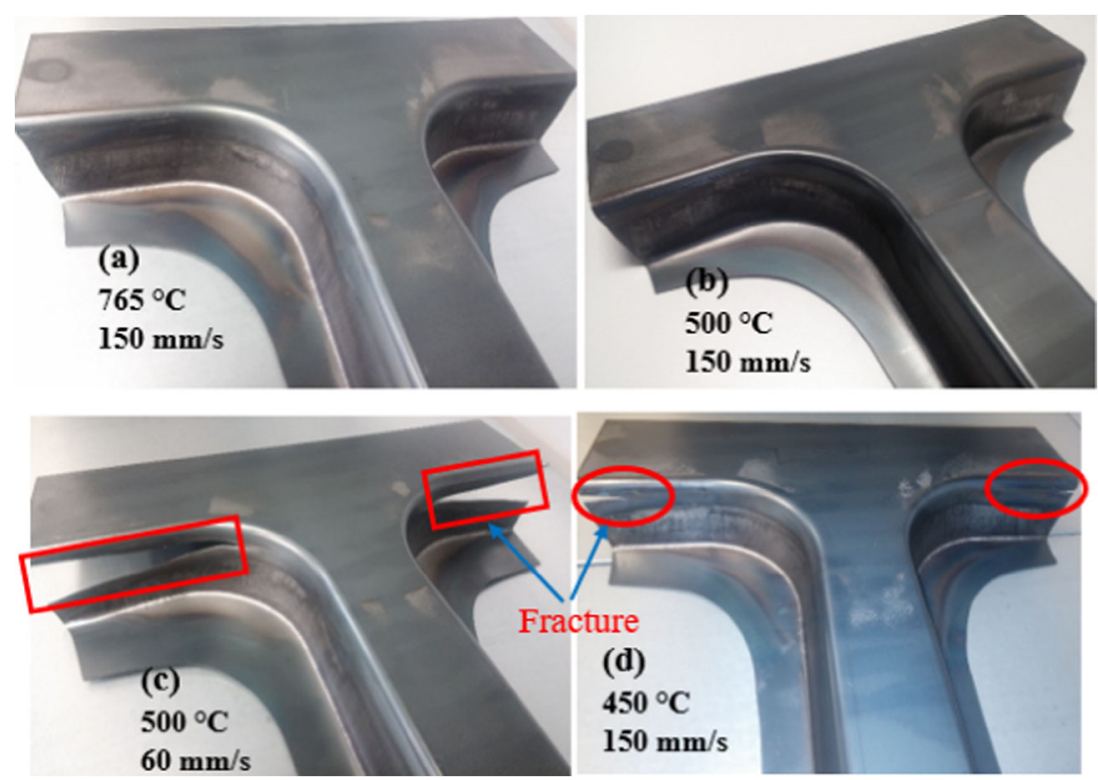

tensile tests were carried out for various stamping conditions. Tensile tests were performed using ASTM E8 sub-size specimen as shown in Fig. 6.

\section{Results and discussion of hot stamping processes}

\subsection{Summary of forming results}

Fig. 7 shows selected results from hot stamping B-Pillars with $50 \mathrm{~mm}$ depth, at the speed of $150 \mathrm{~mm} / \mathrm{s}$ and different temperatures: (a) shows the component formed through the conventional hot stamping process without pre-cooling, at the start stamping temperature of $765^{\circ} \mathrm{C}$; (b) and (c) show the products stamped through the new hot stamping process with precooling to enable the start stamping temperature to be at either $440{ }^{\circ} \mathrm{C}$ (refer to Fig. 7b) or $420^{\circ} \mathrm{C}$ (refer to Fig. 7c). B-Pillars were successfully formed without any fractures using both the conventional process (refer to Fig. 7a) and the new hot stamping process with start stamping temperature of $440{ }^{\circ} \mathrm{C}$ (refer to Fig. 7b). However, when the start stamping

Table 4 B-Pillars hot stamped to the depth of $64 \mathrm{~mm}$ with various process conditions (' $\checkmark$ ' represents that the component was formed without necking/fracture; ' $X$ ' represents that necking/fracture occurred)

\begin{tabular}{llllll}
\hline Forming speed, $\mathrm{mm} / \mathrm{s}$ & \multicolumn{5}{l}{ Actual start stamping temperature $\left({ }^{\circ} \mathrm{C}\right)$} \\
\cline { 2 - 6 } & 765 & 700 & 590 & 500 & 450 \\
\hline 60 & $\checkmark$ & & & $\times$ & \\
150 & $\checkmark$ & $\checkmark$ & $\checkmark$ & $\checkmark$ & $\times$ \\
350 & $\checkmark$ & & $\checkmark$ & $\checkmark$ & $\times$ \\
\hline
\end{tabular}

temperature decreased to $420{ }^{\circ} \mathrm{C}$ through pre-cooling, the product fractured as shown in Fig. 7c. The stamping process was unsuccessful at all forming speeds due to the formation of hard martensite phase at $420{ }^{\circ} \mathrm{C}$ which resulted in product fracture. Table 3 lists the summary of forming results under different process conditions to form products with $50 \mathrm{~mm}$ depth.

The depth of final product influenced the success rate of the new stamping process. When the product depth was increased from 50 to $64 \mathrm{~mm}$, the B-Pillar fractured at the start stamping temperature of $450{ }^{\circ} \mathrm{C}$ (refer to Fig. $8 \mathrm{~d}$ ). This is due to the formation of martensitic phase at below $420{ }^{\circ} \mathrm{C}$ [29] resulted by longer duration of deformation.

The forming speed also influenced the success rate of the new stamping process. For B-Pillar with the depth of $64 \mathrm{~mm}$,

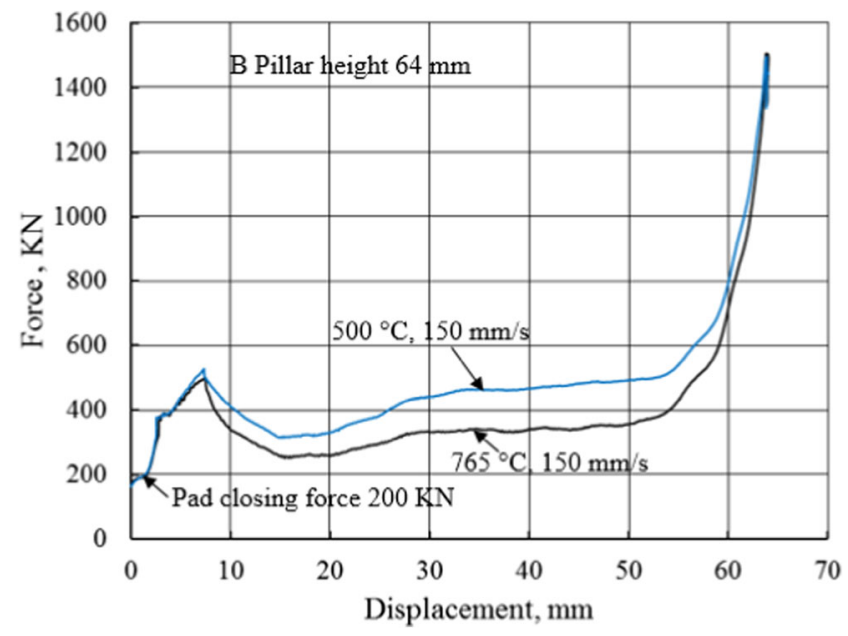

Fig. 9 The force-displacement curves for hot stamping B-Pillars (with drawing depths of $64 \mathrm{~mm}$ ), under a conventional process condition (765 $\left.{ }^{\circ} \mathrm{C}, 150 \mathrm{~mm} / \mathrm{s}\right)$ and a new low-temperature condition $\left(500^{\circ} \mathrm{C}, 150 \mathrm{~mm} / \mathrm{s}\right)$ 
Fig. 10 Thickness distribution of B-Pillars (64 mm depth) hot stamped through a conventional hot stamping process (without pre-cooling) (a), at the start stamping temperature of $765^{\circ} \mathrm{C}$, and a new hot stamping process (with pre-cooling) (b), at the start stamping temperature of $500^{\circ} \mathrm{C}$; both were under the same forming speed of $150 \mathrm{~mm} / \mathrm{s}$

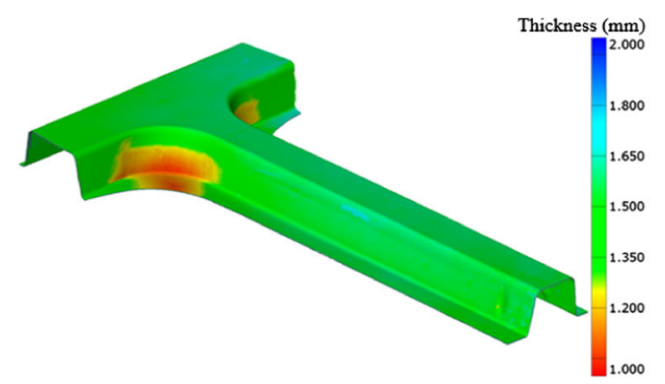

(a)

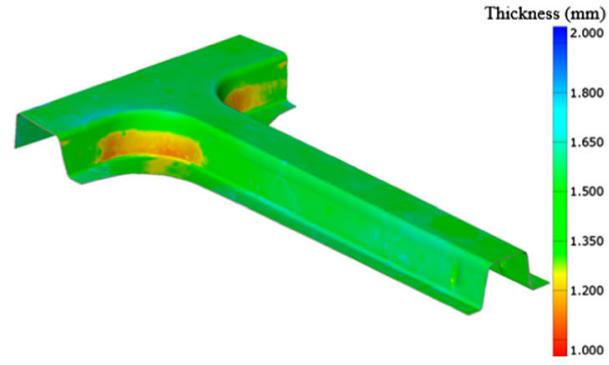

(b) the product formation was successful in the conventional hot stamping processes at $765{ }^{\circ} \mathrm{C}$ for all three forming speeds of $60 \mathrm{~mm} / \mathrm{s}, 150 \mathrm{~mm} / \mathrm{s}$, and $350 \mathrm{~mm} / \mathrm{s}$ (refer to Fig. 8a). The forming was also successful in the new low-temperature hot stamping processes at $500^{\circ} \mathrm{C}$, with the forming speeds of 150 $\mathrm{mm} / \mathrm{s}$ and $350 \mathrm{~mm} / \mathrm{s}$ (refer to Fig. 8b). However, fracture occurred when the forming speed was reduced to $60 \mathrm{~mm} / \mathrm{s}$ (refer to Fig. 8c). This is because, at a lower forming speed $(60 \mathrm{~mm} / \mathrm{s})$, stamping time was longer which means additional time was available for heat loss from the blank to dies. It led to much reduced ductility due to martensite phase transformation. Table 4 lists the summary of forming results under different process conditions to form products with $64 \mathrm{~mm}$ depth. Fig. 9 shows the comparison of force-displacement curves for two stamping conditions, which are $765{ }^{\circ} \mathrm{C}, 150 \mathrm{~mm} / \mathrm{s}$ and $500{ }^{\circ} \mathrm{C}, 150 \mathrm{~mm} / \mathrm{s}$, representing the conventional and new low-temperature hot stamping processes respectively. The forming force was increased by approx. $29 \%$ for the new process, which was clearly due to the increased flow stress when the material is deformed at a lower temperature. The fact that the decrease of stamping temperature leads to increased stamping force is noted, which would accordingly increase the mechanical work needed for the stamping. However, it is not the most important factor to be considered in hot stamping because the major energy consumption is for heat treatment and the forming force is relatively low compared with cold forming.

\subsection{Investigation of as-formed thickness distribution}

The formability in both conventional (without pre-cooling) and new (with pre-cooling) hot stamping processes were further investigated by measuring the thickness distribution of the final products. Fig. 10 shows the thickness distribution of hot-stamped B-Pillars with a depth of $64 \mathrm{~mm}$ formed at the speed of $150 \mathrm{~mm} / \mathrm{s}$ through both a conventional hot stamping process (without pre-cooling) at the start stamping temperature of $765{ }^{\circ} \mathrm{C}$ (refer to Fig. 10a) and a new hot stamping process (with pre-cooling) at $500{ }^{\circ} \mathrm{C}$ (refer to Fig. $10 \mathrm{~b}$ ). The maximum thinning of products formed at $765^{\circ} \mathrm{C}$ and $500{ }^{\circ} \mathrm{C}$ was $29 \%$ and $25 \%$, respectively. Fig. 11 (a) to (d) shows the thickness of the critical section of B-Pillars (refer to Fig. 5 for critical section) formed under different start stamping temperatures: $765^{\circ} \mathrm{C}$ without pre-cooling and 700 ${ }^{\circ} \mathrm{C}, 590{ }^{\circ} \mathrm{C}$, and $500{ }^{\circ} \mathrm{C}$ with pre-cooling. The maximum thinning was similar in the range of $25-29 \%$. Minimum thickness in the nearly flat region around point $\mathrm{B}$ was also measured by using a mechanical round-headed micrometre, to compare the measurements from the 3D scanner. Results were summarised in Table 5. It could be seen that the errors were around $\pm 0.01 \mathrm{~mm}$ (less than $\pm 1 \%$ ). It could be stated that the new process with pre-cooling, at the start stamping temperature of $500{ }^{\circ} \mathrm{C}$, allowed more uniform thickness to be obtained, compared with the B-Pillar formed at $765^{\circ} \mathrm{C}$. The reason could be that, at a lower stamping temperature, boron steel
Fig. 11 Thickness distribution of B-Pillars (64 mm depth) at a critical section A-B, produced through the conventional hot stamping process without precooling at (a) $765^{\circ} \mathrm{C}$, and the new hot stamping process with precooling at (b) $700{ }^{\circ} \mathrm{C}$, (c) $590{ }^{\circ} \mathrm{C}$, and (d) $500{ }^{\circ} \mathrm{C}$, under the same forming speed of $150 \mathrm{~mm} / \mathrm{s}$ (the temperatures given were start stamping temperatures)

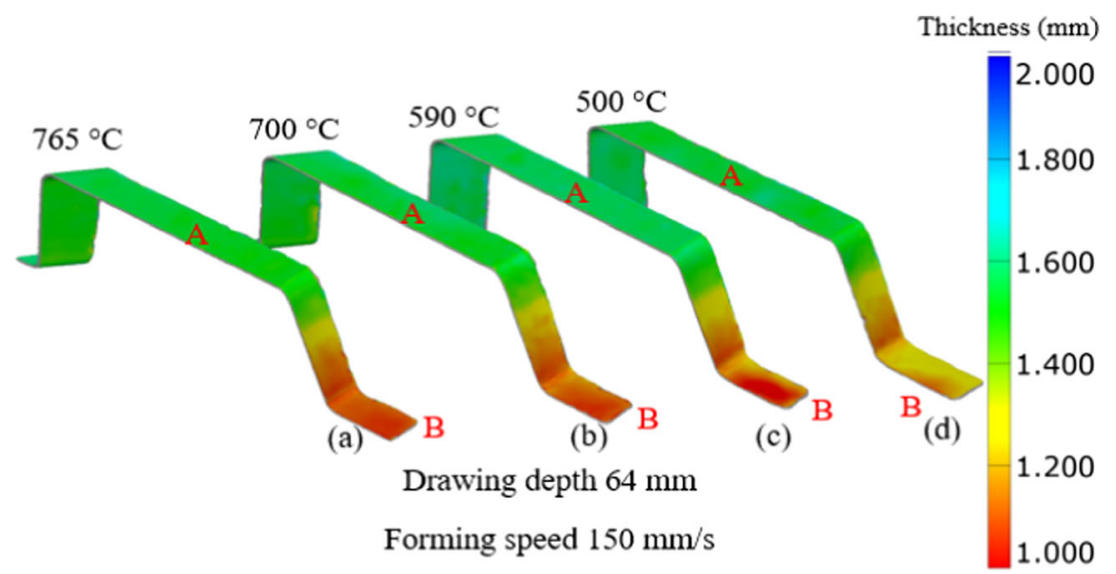


Table 5 Comparison of thickness measurements, for the minimum thickness around point B in Fig. 11, for the parts with the height of $64 \mathrm{~mm}$ (formed at various start stamping temperatures, $150 \mathrm{~mm} / \mathrm{s}$ )

\begin{tabular}{llll}
\hline \multirow{2}{*}{ Start stamping temperature $\left({ }^{\circ} \mathrm{C}\right)$} & \multicolumn{2}{l}{ Flange thickness $(\mathrm{mm})$} \\
\cline { 3 - 4 } & & 3D scanner & Micrometre \\
\hline 765 & Sample 1 & 1.08 & 1.06 \\
700 & Sample 2 & 1.07 & \\
& Sample 1 & 1.06 & 1.05 \\
590 & Sample 2 & 1.06 & \\
500 & Sample 1 & 1.08 & 1.07 \\
& Sample 1 & 1.12 & 1.14 \\
\hline
\end{tabular}

blank might have better temperature uniformity during forming. In addition, a higher value of strain hardening for the material at a lower deformation temperature could be another factor to restrain localised deformation. The similar observation was found in deep drawing of aluminium alloy 7075 using hot stamping process where the thickness uniformity was better at a lower temperature range [30] (Fig. 11).

\subsection{Examination of post-formed properties}

The room-temperature tensile properties of workpieces, which were cut from as-formed parts produced through different hot stamping processes and conditions, were tested and representative results are presented in Fig. 12. The results confirmed that a similar strength level $(\sim 1400 \mathrm{MPa})$ was achieved through both the conventional and the new hot stamping processes, for both product depths. The strength is the essential property requirement in hot stamping for UHSS automotive parts. Figure 13 shows microstructure and micro-hardness analysis of boron steels hot stamped under representative

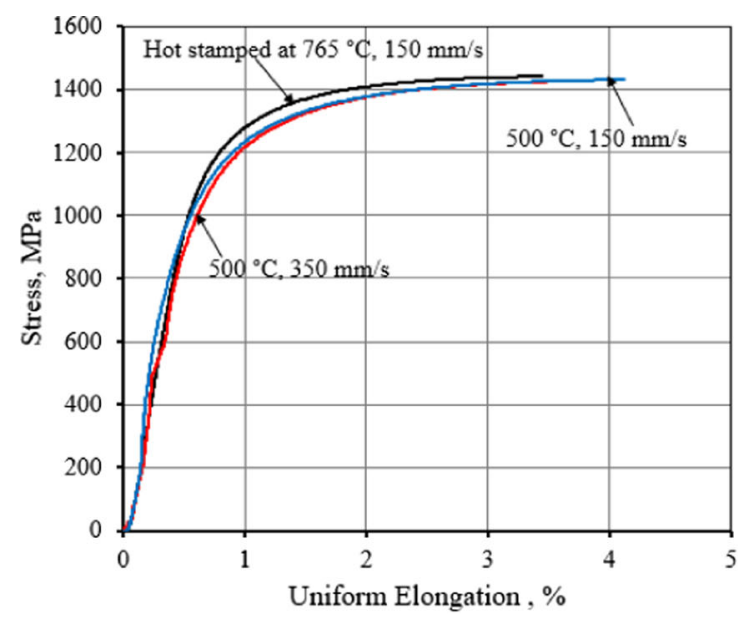

(a) Depth: $64 \mathrm{~mm}$.

Fig. 12 True stress-true strain curves of boron steels cut from hotstamped B-Pillars, with drawing depths of $64 \mathrm{~mm}$ (a) and $50 \mathrm{~mm}$ (b), conditions through both the conventional processes $\left(765^{\circ} \mathrm{C}\right.$, $150 \mathrm{~mm} / \mathrm{s})$ and the new processes $\left(700{ }^{\circ} \mathrm{C}, 150 \mathrm{~mm} / \mathrm{s} ; 590^{\circ} \mathrm{C}\right.$, $150 \mathrm{~mm} / \mathrm{s} ; 500^{\circ} \mathrm{C}, 350 \mathrm{~mm} / \mathrm{s}$ ). The initial Vickers hardness of the as-received material was $170 \mathrm{HV}$. The Vickers hardness values for all the successful parts were confirmed to be greater than $450 \mathrm{HV}$, which indicates that martensitic transformation was achieved in both the hot stamping processes, which was further proven through microstructure observation by using scanning electron microscopes (SEM).

\section{Studies on in-die quenching time}

\subsection{Experimental details}

To understand the significance of the new hot stamping process in reducing cycle time, in-die quenching experiments were carried out. The in-die quenching tests were performed on a $250-\mathrm{kN}$ hydraulic test machine as shown in Fig. 14a and the test setup is shown in Fig. 14b. The entire tool setup was mounted onto two gas spring cylinders and the required dieworkpiece contact pressure was controlled by varying the gas pressure. The quenching dies, including top and bottom dies, were made from AISI H13 steel and were heated to required temperatures by using electric band heaters. Two band heaters were placed around both top and bottom die peripheries, which could ensure uniform heating compared with other heating techniques [31]. A circular boron steel blank with the diameter of $80 \mathrm{~mm}$ and the thickness of $1.5 \mathrm{~mm}$ was used as the test-piece. The cross-sectional schematics in Fig. 14c show the arrangement of dies, band heaters, and a test-piece under testing. Three pairs of K-type thermocouples were rigidly inserted into the bottom die and the thermocouples are $3.19 \mathrm{~mm}$ (TC2), $3.83 \mathrm{~mm}$ (TC3), and $4.68 \mathrm{~mm}$ (TC4) away from the contact surface of the bottom die. TC2 was used to

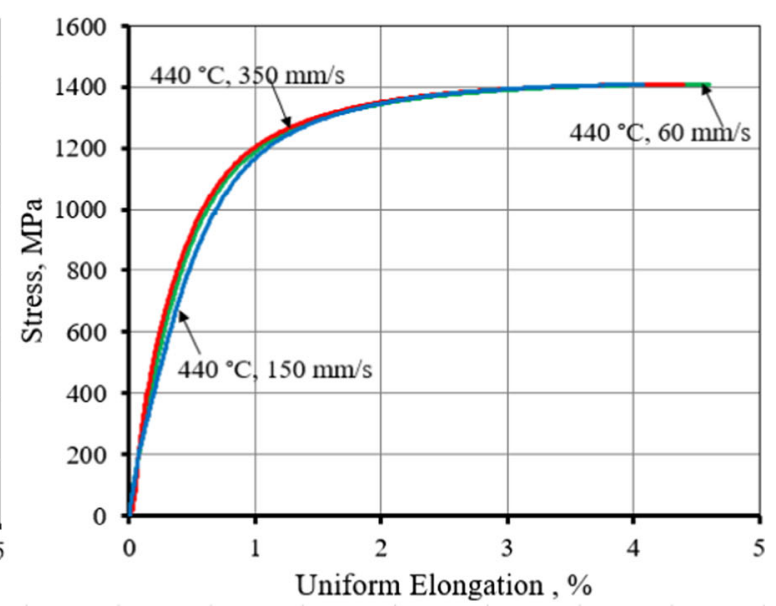

(b) Depth: $50 \mathrm{~mm}$.

which were produced under various process conditions (detailed in the figures) 
Fig. 13 Microstructure and micro-hardness analysis of boron steels hot stamped under various test conditions. a $765^{\circ} \mathrm{C}, 150$ $\mathrm{mm} / \mathrm{s}$. b $700{ }^{\circ} \mathrm{C}, 150 \mathrm{~mm} / \mathrm{s}$. c 590 ${ }^{\circ} \mathrm{C}, 150 \mathrm{~mm} / \mathrm{s}$. d $500{ }^{\circ} \mathrm{C}, 350 \mathrm{~mm} /$ $\mathrm{s}$

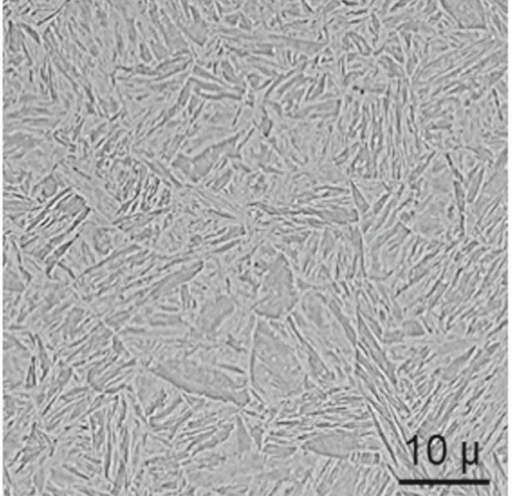

$460 \mathrm{HV}$

(a) $765{ }^{\circ} \mathrm{C}, 150 \mathrm{~mm} / \mathrm{s}$.

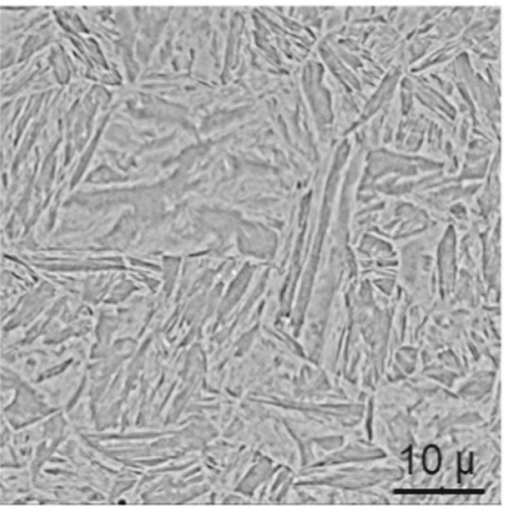

$459 \mathrm{HV}$

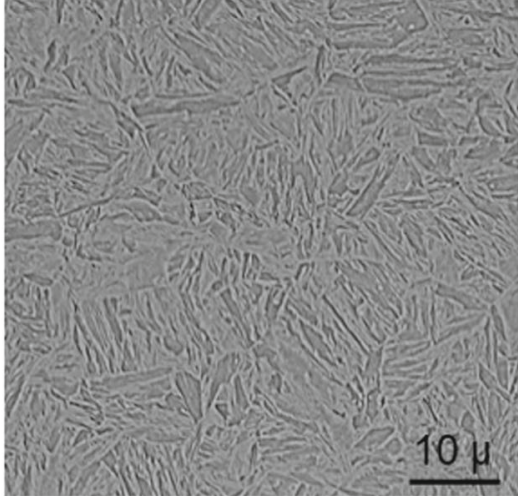

$457 \mathrm{HV}$

(b) $700{ }^{\circ} \mathrm{C}, 150 \mathrm{~mm} / \mathrm{s}$.

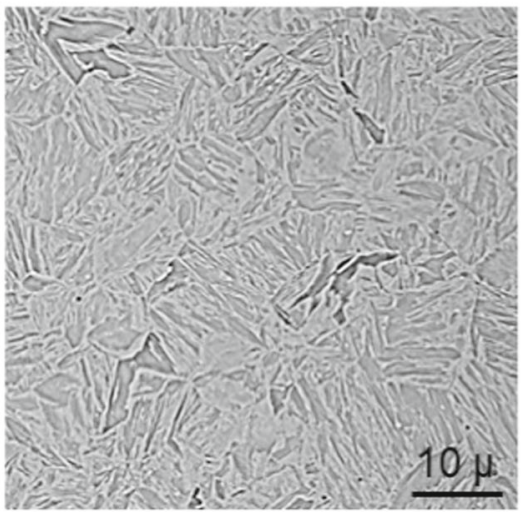

$454 \mathrm{HV}$

(d) $500{ }^{\circ} \mathrm{C}, 350 \mathrm{~mm} / \mathrm{s}$. (c) $590{ }^{\circ} \mathrm{C}, 150 \mathrm{~mm} / \mathrm{s}$.

range of combinations of initial tool temperatures, contact pressure, and workpiece start quenching temperature were defined and detailed in the next subsection.

According to the difference between measured and set temperatures, the temperature controller applies an electrical current to band heaters. Thermocouples TC 3 and TC4 were connected to thermocouple data logger to record the temperatures during the quenching period. A pair of K-type stainless steel thermocouple (TC1) in $0.5 \mathrm{~mm}$ diameter was embedded into test-piece in parallel to the blank surfaces, not to affect the contact between the workpiece and dies during in-die quenching. During testing, a test-piece was heated to a desired temperature in an electrical furnace; then, it was quickly transferred to a quenching tool and was pressed between preheated top and bottom dies. It is noted that the pre-cooling is very difficult to control without employing a fully automatic system; hence, to imply the experiments in laboratory, the material was heated to a temperature just above the start quenching temperature (rather than austenitisation completion temperature) for each test condition. The temperature histories of both workpiece and dies were recorded during the entire process. To investigate the in-die quenching time required to reach $250{ }^{\circ} \mathrm{C}$ (which is below martensite transformation finish temperature), a

\subsection{Result and discussion on in-die quenching time}

The influence of workpiece start quenching temperature, initial die temperature, and die-workpiece contact pressure on in-die quenching time during hot stamping processes was analysed and is presented in Figs. 15, 16, and 17.

\subsubsection{Effect of workpiece start quenching temperature}

The temperature-cooling time curves obtained for various workpiece start quenching temperatures of $740{ }^{\circ} \mathrm{C}, 600{ }^{\circ} \mathrm{C}$, and $520{ }^{\circ} \mathrm{C}$, at initial die temperature of $70{ }^{\circ} \mathrm{C}$ and dieworkpiece contact pressure of $20 \mathrm{MPa}$, are shown in Fig. 15. The graph shows that the quenching time was $4 \mathrm{~s}, 2.3 \mathrm{~s}$, and $1.8 \mathrm{~s}$ for in-die quenching from $740{ }^{\circ} \mathrm{C}, 600{ }^{\circ} \mathrm{C}$, and $510{ }^{\circ} \mathrm{C}$ respectively. It is evident that a decrease in workpiece start quenching temperature by using low-temperature hot 
Fig. 14 Experimental setup for quenching test. a Equipment setup. b Quenching die setup. c Schematics illustrating the control of tool heating and tool temperature measurement for the quenching tool

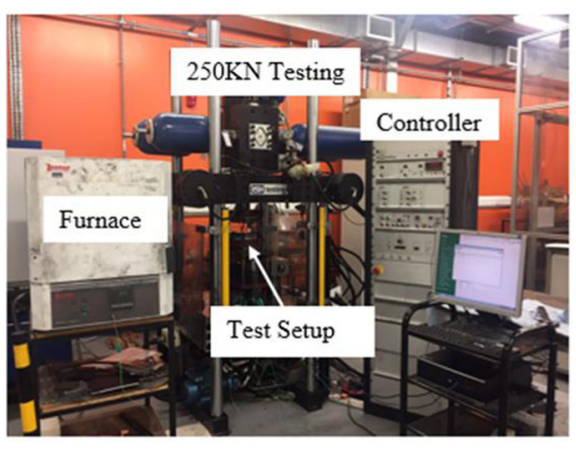

(a) Equipment set-up.

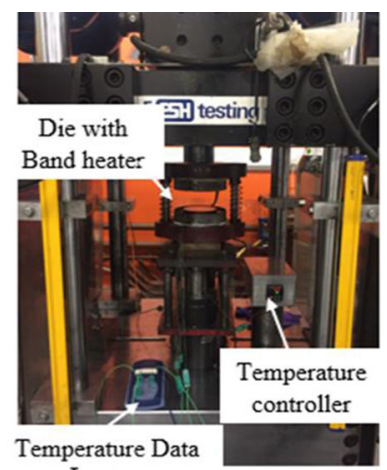

Logger

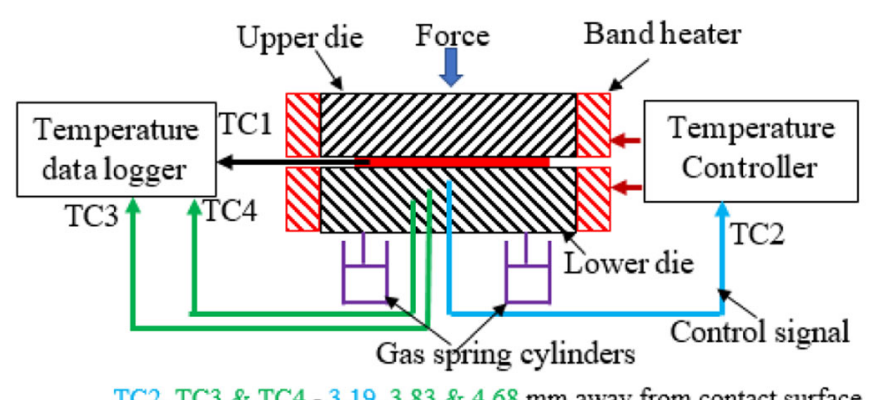

TC2, TC3 \& TC4 - 3.19, $3.83 \& 4.68 \mathrm{~mm}$ away from contact surface

(c) Schematics illustrating the control of tool heating and tool temperature measurement for the quenching tool. stamping can result in a significant reduction (55\% less time) in quenching time.

\subsubsection{Effect of initial die temperature}

Two defined start quenching temperatures $740{ }^{\circ} \mathrm{C}$ and $520^{\circ} \mathrm{C}$ were selected as the representative temperatures to simulate the conventional and the new hot stamping processes, respectively. As shown in Fig. 16a and b, the in-die quenching time with various initial die temperatures of $170^{\circ} \mathrm{C}, 100^{\circ} \mathrm{C}$, and 70

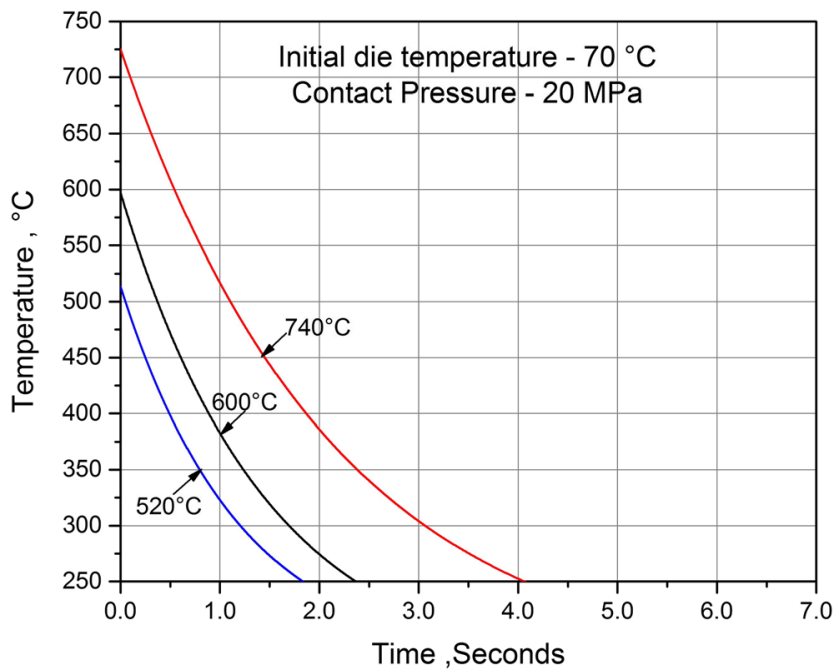

Fig. 15 Effect of workpiece start quenching temperature on in-die quenching time
${ }^{\circ} \mathrm{C}$, under the die-workpiece contact pressure of $20 \mathrm{MPa}$, was studied. It is noted that the actual start quenching temperatures varied within $\pm 20^{\circ} \mathrm{C}$ of the defined temperatures in the experiments and the actual temperatures were measured and are presented in all figures in the section.

With initial tool temperature of $170{ }^{\circ} \mathrm{C}, 100^{\circ} \mathrm{C}$, and $70^{\circ} \mathrm{C}$, the quenching time required was $12.5 \mathrm{~s}, 4.4 \mathrm{~s}$, and $4 \mathrm{~s}$ from $740{ }^{\circ} \mathrm{C}$, whereas it was $8 \mathrm{~s}, 2.5 \mathrm{~s}$, and $2 \mathrm{~s}$ from $520^{\circ} \mathrm{C}$. The quenching time is shorter when the initial tool temperature is lower for both start quenching temperatures of $740^{\circ} \mathrm{C}$ and 520 ${ }^{\circ} \mathrm{C}$. This is because at a lower initial die temperature, the temperature difference between the workpiece and tool is higher, which increases the driving force for cooling rate. It also shows that, for the new hot stamping processes, the quenching time was significantly reduced with each tool temperature compared with the conventional processes.

\subsubsection{Effect of die-workpiece contact pressure}

Figure $17 \mathrm{a}$ and $\mathrm{b}$ shows the temperature-cooling time curves obtained for the die-workpiece contact pressure of $1 \mathrm{MPa}, 5$ $\mathrm{MPa}$, and $20 \mathrm{MPa}$ with the initial die temperature of $100{ }^{\circ} \mathrm{C}$ and workpiece start quenching temperature of $740{ }^{\circ} \mathrm{C}$ and 520 ${ }^{\circ} \mathrm{C}$ respectively. With die-workpiece contact pressure of 1 $\mathrm{MPa}, 5 \mathrm{MPa}$, and $20 \mathrm{MPa}$, the quenching time required was $6.3 \mathrm{~s}, 5.1 \mathrm{~s}$, and $4.4 \mathrm{~s}$ quenched from $740{ }^{\circ} \mathrm{C}$, whereas it was $5.7 \mathrm{~s}, 2.3 \mathrm{~s}$, and $2.3 \mathrm{~s}$ quenched from $520^{\circ} \mathrm{C}$. It can be seen that, under both start quenching temperatures corresponding 


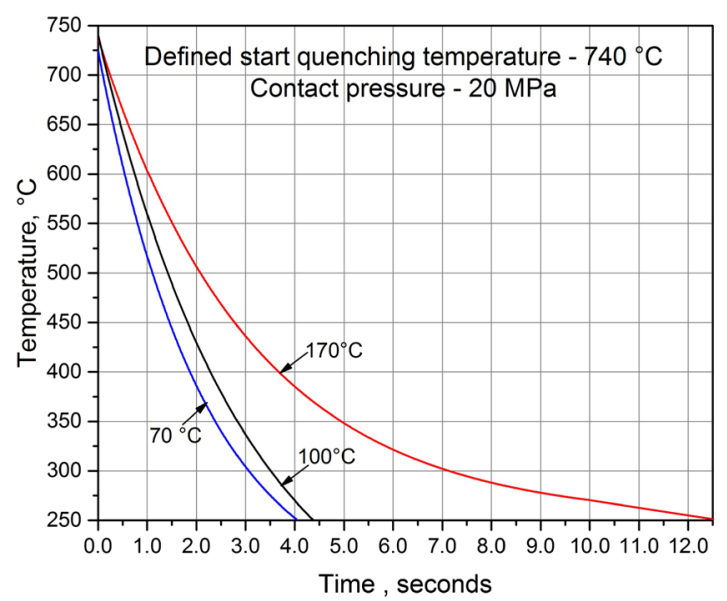

(a) Conventional hot stamping process without pre-cooling.

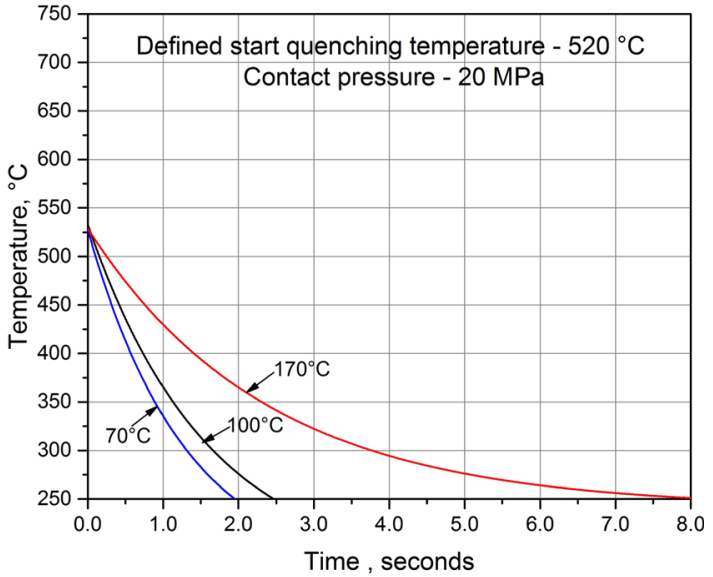

(b) New hot stamping process with pre-cooling.

Fig. 16 Effect of initial die temperature on in-die quenching time. a Conventional hot stamping process without pre-cooling. b New hot stamping process with pre-cooling

to both processes, it took longer time to quench the workpiece at a low die-workpiece contact pressure of $1 \mathrm{MPa}$ compared with higher pressures of $5 \mathrm{MPa}$ and $20 \mathrm{MPa}$, whereas no noticeable difference was found between 5 and $20 \mathrm{MPa}$. The is because the increase in contact pressure increases the real surface contact area and thus increases the average interface heat transfer coefficient which can result in a higher cooling rate, while the effect becomes minimal when the contact pressure reaches a certain level $[32,33]$. Again, it was evident that less quenching time was taken under all contact pressures for the low-temperature hot stamping.

\subsection{Benefits of the new hot stamping process}

A summary of the in-die quenching experimental results is presented in Fig. 18 to demonstrate the advantage of the new hot stamping processes in quenching time reduction.

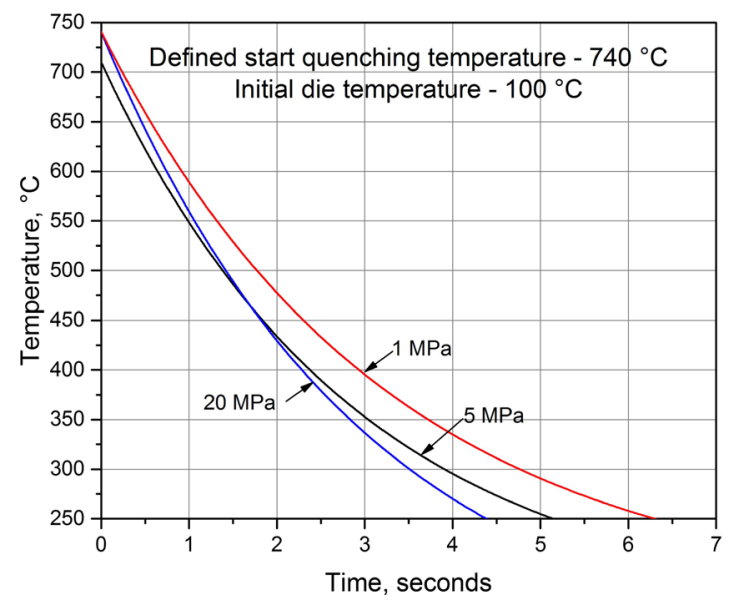

(a) Conventional hot stamping process without pre-cooling.
In a conventional hot stamping process (defined start quenching temperature of $740{ }^{\circ} \mathrm{C}$ ), the in-die quenching time required to cool down the product to $250{ }^{\circ} \mathrm{C}$ was $6.3 \mathrm{~s}$ for the lower $(1 \mathrm{MPa})$ and $4.4 \mathrm{~s}$ for the higher $(20 \mathrm{MPa})$ contact pressure. However, in the new hot stamping process with precooling (defined start quenching temperature of $520^{\circ} \mathrm{C}$ ), indie quenching time required was $5.7 \mathrm{~s}$ and $2.3 \mathrm{~s}$ for the lower and higher contact pressure, respectively. Therefore, it is valid to claim that the new process can reduce the in-die quenching time by $48 \%$ or above. It is noted that the decrease of the in-die quenching time is nearly the same as the additional pre-cooling time for the new process, which means the total process time for a standalone cycle of the conventional process and the new process would be nearly the same. However, for continuous volume/mass production, since the parts would be shifted from one stage to the other at the frequency of the slower one (which is the forming and in-die quenching stage here), the new low-

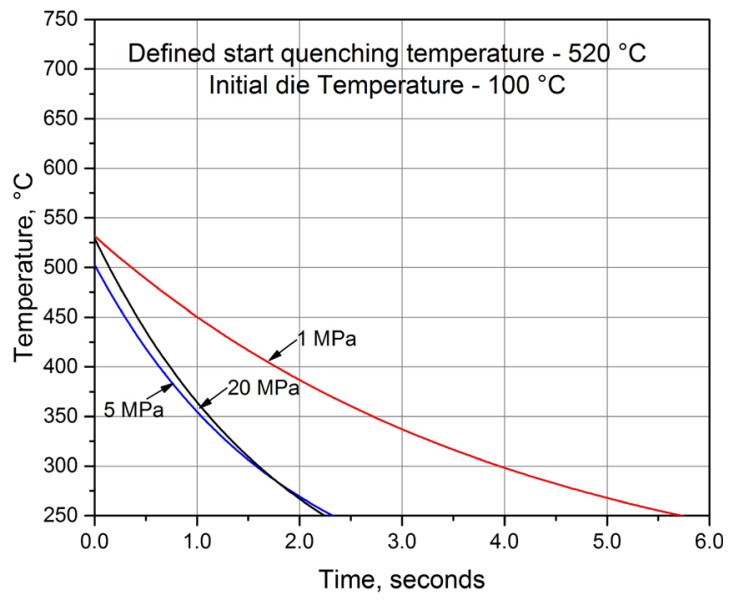

(b) New hot stamping process with pre-cooling.

Fig. 17 Effect of die-workpiece contact pressure on in-die quenching time. a Conventional hot stamping process without pre-cooling. $\mathbf{b}$ New hot stamping process with pre-cooling 


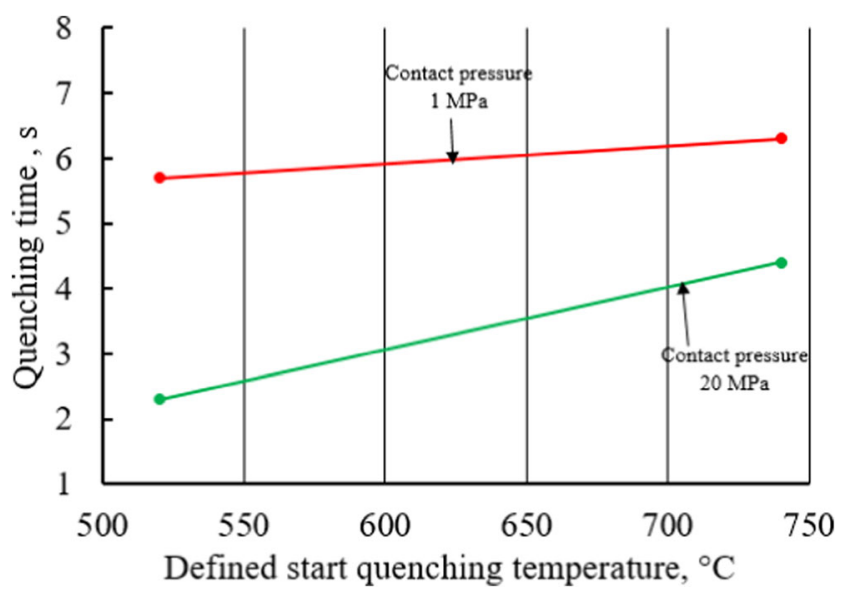

Fig. 18 In-die quenching time for different start quenching temperatures under different die-workpiece contact pressures at an initial die temperature of $100{ }^{\circ} \mathrm{C}$

temperature hot stamping process is beneficial in the way of increased productivity.

It is worth mentioning that, due to the simplification of the thermal cycle, the data obtained from this set of tests would not be identical as the data obtained from real hot stamping processes involving phase transformations. This is because the thermal diffusivity of the different microstructures would be different [34], while the material microstructure in this set of tests was mainly ferrite-pearlite through the whole heating and cooling cycle, without phase transformations of ferrite-pearlite to austenite and austenite to martensite. In addition, the martensite transformation during cooling would cause the release of the latent heat and the increase of volume. The former one would result in increased heat to extract thus potentially longer cooling time; the latter one would potentially result in increased interfacial heat transfer coefficient thus less cooling time. This work did not include detailed studies on this aspect. According to references [34, 35], the effect of latent heat during cooling caused by austenite to martensite transformation would become neglectable when the contact pressure is high (20 MPa or above). In addition, the difference in thermal diffusivity would be within $10 \%$. Therefore, it is valid to claim that the trend founded through this set of experiments is correct and the exact values of cooling time are not accurate but could be used as a reference for industrial applications.

It is also worth mentioning that, for the new process, the thermo-mechanical fatigue cycle of the die material will be different, with larger stresses but lower temperatures, which would potentially have negative and positive impacts, respectively, on the die duration. This may be important for the die life and could be an interesting point for future investigation.

\section{Conclusions}

A new low-temperature hot stamping process with precooling for $22 \mathrm{MnB} 5$ boron steel has been successfully demonstrated by hot stamping demonstrator B-Pillars, with both $50 \mathrm{~mm}$ and $64 \mathrm{~mm}$ drawing depths, using an advanced inhouse prototyping line. Hot stamping experiments were carried out for a wide range of stamping temperatures and forming speeds. The potential advantage of hot stamping at low temperature was assessed through post-form examination of the hot-stamped parts and in-die quenching experiments. It has been proven that the final thickness distribution, as well as the mechanical properties and microstructures, of the B-Pillars produced through the new process is more than acceptable. More importantly, the productivity can be increased due to significantly reduced in-die quenching when the new process is employed.

Acknowledgements The authors would like to thank Tata Steel for the financial support provided for this project. The authors also like to acknowledge Gerben Botman, Menno De Bruine, and Peter Jones of Tata Steel Europe and Asit Kumar Choudhary and Apparao Chintha of Tata Steel Ltd. for their experimental support and valuable suggestions.

Open Access This article is distributed under the terms of the Creative Commons Attribution 4.0 International License (http:// creativecommons.org/licenses/by/4.0/), which permits unrestricted use, distribution, and reproduction in any medium, provided you give appropriate credit to the original author(s) and the source, provide a link to the Creative Commons license, and indicate if changes were made.

\section{References}

1. Tolouei R (2015) Carbon policies targeting road transport: is there a safety consequence. Transportation Research Procedia 8:259-271

2. Volvo (2016) V90 car body presentation. Presented at EuroCarBody - 18th global car body benchmarking conference. In

3. Lin J (2015) Fundamentals of materials modelling for metals processing technologies: theories and applications. World Scientific Publishing Co Inc.

4. Keeler SP (1965) Determination of forming limits in automotive stampings. SAE Technical Paper

5. Maeno T, Mori K-I, Fujimoto M (2015) Improvements in productivity and formability by water and die quenching in hot stamping of ultra-high strength steel parts. CIRP Ann Manuf Technol 64(1): 281-284

6. Lim W-S, Choi H-S, S-y A, Kim B-M (2014) Cooling channel design of hot stamping tools for uniform high-strength components in hot stamping process. Int J Adv Manuf Technol 70(5):11891203

7. Salamon U, Aspacher J (2012) Method for shaping a blank, and cooling device for a blank. U.S. Patent 8,272,245

8. Hoffmann H, So H, Steinbeiss H (2007) Design of hot stamping tools with cooling system. CIRP Ann Manuf Technol 56(1):269272

9. Sikora S, Lenze F (2006) Hot-forming-process important parameters for the production of high-strength BIW parts. In: IDDRG conference. Porto, pp 295-301 
10. Hardell J, Pelcastre L, Prakash B (2010) High-temperature friction and wear characteristics of hardened ultra-high-strength boron steel. Proceedings of the institution of mechanical engineers, Part J: Journal of Engineering Tribology 224(10):1139-1151

11. Schrenk M, Krenn S, Ripoll MR, Nevosad A, Paar S, Grundtner R, Rohm G, Franek F (2016) Statistical analysis on the impact of process parameters on tool damage during press hardening. $\mathrm{J}$ Manuf Process 23:222-230

12. Balint D, Dean TA, Lin J (2014) A method of forming parts from sheet steel. U.S. Patent Appl 14(/347):531

13. Ota E, Yogo Y, Iwata T, Iwata N, Ishida K, Takeda K (2014) Formability improvement technique for heated sheet metal forming by partial cooling. In: Key engineering materials. Trans Tech Publ, pp 279-283

14. Chang Y, Wang C, Zhao K, Dong H, Yan J (2016) An introduction to medium-Mn steel: metallurgy, mechanical properties and warm stamping process. Mater Des 94:424-432

15. Li X, Chang Y, Wang C, Hu P, Dong H (2017) Comparison of the hot-stamped boron-alloyed steel and the warm-stamped mediumMn steel on microstructure and mechanical properties. Mater Sci Eng A 679:240-248

16. Matsumoto T, Li N, Shi X, Lin J (2016) An investigation of deformation effects on phase transformation in hot stamping processes. SAE Int J Mater Manuf 9(2):501-505

17. Yang S, Wang L (2018) Study on selective cooling of ultra high strength steel car body in hot forming. Int J Adv Manuf Technol 97(1):1583-1590. https://doi.org/10.1007/s00170-018-1864-6

18. Verloop WC, Van GMJ, Van TRT, Hensen GC (2012) Method to produce a hot formed part, and part thus formed. WO2012097976A1

19. Gerlach L, Werbs M (2010) Method for mould annealing with intermediate cooling. WO2010020212A1

20. Larsson J, Akerstrom P, Berglund D (2015) Method of press hardening a steel sheet blank. U.S. Patent 8,968,496

21. Yokoi T, Yamada T, Kawano O (2013) Hot rolled steel sheet and method for production thereof. CN104053806B

22. Becker JU, Bian J, Heller T, Schoenenberg R, Thiessen RG, Zeizinger S, Rieger T, Bulters O (2017) High-strength flat steel product and method for producing same. U.S. Patent 9,650,708

23. Okita K, Naitou J, Ikeda S (2016) Press-forming product manufacturing method and press-forming facility. U.S. Patent 9 , 469,891
24. Kondo M, Suzuki S, Tomokiyo T, Nishizawa K, Suzuki T, Ishiguro Y, Kai H (2014) High-strength press hardened article, and manufacturing method therefor. U.S. Patent 8,858,735

25. Kolnberger S, Schwinghammer H, Kurz T, Klein M (2014) Method for producing hardened components and a structural component produced using said method. WO2014114420A1

26. Divjak F, Scheuring B (2010) Method and furnace for making a metal workpiece with regions of different ductility. WO2010089103A1

27. Ganapathy M (2018) Hot stamping of complex shaped boron steel panels. PhD Thesis, Imperial College London

28. Somani MC, Karjalainen LP, Eriksson M, Oldenburg M (2001) Dimensional changes and microstructural evolution in a Bbearing steel in the simulated forming and quenching process. ISIJ Int 41(4):361-367

29. Karbasian H, Tekkaya AE (2010) A review on hot stamping. J Mater Process Technol 210(15):2103-2118

30. Xiao W, Wang B, Zheng K (2017) An experimental and numerical investigation on the formability of AA7075 sheet in hot stamping condition. Int J Adv Manuf Technol 1-11

31. Bai Q, Lin J, Zhan L, Dean T, Balint D, Zhang Z (2012) An efficient closed-form method for determining interfacial heat transfer coefficient in metal forming. Int J Mach Tools Manuf 56:102-110

32. Zhang Z, Gao P, Liu C, Li X (2015) Experimental and simulation study for heat transfer coefficient in hot stamping of high-strength boron steel. Metall Mater Trans B 46(6):2419-2422

33. Merklein M, Svec T (2013) Hot stamping: manufacturing functional optimized components. Prod Eng 7(2-3):141-151

34. Kuepferle J, Wilzer J, Weber S, Theisen W (2015) Thermo-physical properties of heat-treatable steels in the temperature range relevant for hot-stamping applications. J Mater Sci 50(6):2594-2604

35. Abdulhay B, Bourouga B, Dessain C, Brun G, Wilsius J (2011) Development of estimation procedure of contact heat transfer coefficient at the part-tool interface in hot stamping process. Heat Transfer Eng 32(6):497-505

Publisher's note Springer Nature remains neutral with regard to jurisdictional claims in published maps and institutional affiliations. 